\title{
Children and Horror after PG-13: The Case of The Gate
}

\author{
FILIPA ANTUNES, University of East Anglia
}

\begin{abstract}
The paper analyses the tensions in the text, production and reception of the children's horror film The Gate (Tibor Takács, 1987) relating to the sustained ambiguity around the Motion Picture Association of America's PG-13 classification. I suggest that the late 1980s was a moment of transition toward new attitudes about the horror genre and children. To develop this argument, the paper explores the main issues raised in critical opinion about the film at the time of its release: notions on what the horror genre is or should be; the changing assumptions about its audiences (namely the shift away from an adults-only perspective); and moral panics triggered by transitioning social values.
\end{abstract}

These struggles are suggested also in the creative clashes between the writer and director of The Gate: where one wanted to make a traditional R-rated horror, the other was adamant about it being a positive fairy-tale for pre-teens. The paper analyses the way this conflict is reflected in the film's representations of children and suggests that its resolution in a vision of child empowerment (narratively and critically) indicates a move away from traditional assumptions about the horror genre, as well as childhood. Through this analysis, the paper also seeks to understand how PG-13 was perceived in the late 1980s, particularly in terms of its implied audience and its relationship with the genre of horror. Through this focus on the relationship between ratings, creative choices and conflicting attitudes, the paper proposes the idea of two intertwined cultural shifts: toward a more segmented view of childhood, in the emergence of the pre-teen as a demographic, and a more open definition of horror and its audiences.

\section{KEYWORDS}

Childhood, tweens, film ratings, horror, reception, the 1980s.

\section{Introduction}

The Motion Picture Association of America's (MPAA) PG-13 rating and the horror genre have always had a troubled relationship. Despite the large number of PG-13 horror features, many of which become box office successes, the coupling of the two often meets opposition. 'For many horror junkies' the 'stamp of approval' (Crow 2013) is given by the R rating, whereas PG-13 has been dubbed 'the certificate of unscariness' (Lynch 2013), presumably because it allows children to watch the film unsupervised. Outside of horror fandom, defenders of the 'ratings creep' hypothesis (Thompson 2004) have also condemned the PG-13 rating for allowing adult content, including horror, to be screened to children. 
The problem of children, and specifically the problem of children watching horror, is a central issue with PG-13, harking back to 1984, when debates around the violence and horror in Gremlins (Joe Dante, 1984) and Indiana Jones and the Temple of Doom (Steven Spielberg, 1984) prompted the MPAA's introduction of the category. Although studios were favourable to the new rating because of the increased flexibility it promised, some critics worried that this new rating would allow horror and other adult content to seep below the restricted frontier imposed by the R rating. (Prince 2002, 367). Both of these predictions came true to an extent, as, by toning down intensity, filmmakers could now release horror films for all audiences, not just adults.

And, indeed, this is what happened. The late 1980s saw a number of child-oriented horror titles released under the PG-13 classification: Critters (Stephen Herek, 1986) and its sequels (1988, 1991 and 1992), as well as The Gate (Tibor Takács, 1987), The Monster Squad (Fred Dekker, 1987) and Lady in White (Frank LaLoggia, 1988), among others. These were films intended by their filmmakers to fit the horror genre but which, by virtue of the new rating, targeted themselves almost exclusively to a young demographic, challenging the notion of horror as a restricted genre not suitable for children.

It is useful to point out that debates over PG-13 at the time of its creation were often tied to the distinctions 'between teenagers and preteens' (Vaugh 2006, 117), indicating that PG-13 signposted a social and cultural separation of the two demographics - and, correspondingly, a shift in notions of suitability. Nevertheless, this distinction between teens and pre-teens was not clear, even after PG13 was established. Talking about his experience with The Gate, which is aimed at pre-teens, Takács has said: 'People really never talked about tweens as an age group back then. Now Disney specifically caters to them quite a bit. At the time, though, people just lumped tweens in with teenagers' (Saucedo 2012).

If a distinction between teenagers and pre-teens as different age groups was only in its inception stage in the late 1980s, and if this distinction is intertwined with the PG-13 audience, then two questions arise: how was the PG-13 horror audience conceptualised? And how is the emergence of this new audience related to changing understandings of the horror genre? To answer these questions, I will take The Gate as my case study. This joint USA/Canada production was a box office success of 1987 (Box Office Mojo) and currently enjoys a quiet reputation as a 'cult hit' (Orange 2009) and a 'classic horror' that 'traumatized a generation' (Webb 2012). But despite its achievements, The Gate was a conflicted production, stuck between the different creative visions of Michael Nankin, the film's writer, who wanted to make a traditional adult-oriented, R-rated horror film, and the director, who was adamant about this being an unrestricted fairy-tale for pre-teens.

Critical reception was also mixed. If some found it 'sweet' (Steinmetz 1987), others, like Kim Newman, described The Gate as one of the 'kiddie comedies' that 'reduce the genre to the level of Scooby-Doo, Where Are You?' (Newman 1988, 204). Along similar lines, Andrew Dowler of Canada Cinema wrote: 'There is one thing, and one thing only, worth saying about The Gate: it is a vicious, venal lie, a corruption and denial of the highest values of art and the core value of fairy tales' (Dowler 1987). Both of these critics suggested that The Gate did not achieve anything of note, artistically or otherwise: for Dowler it is merely 'decent', for Newman an irrelevant example of 'safe horror'. These comments on the film's supposedly undeserved notoriety were echoed by other critics: Gordon Walter refers to the 'rather routine horror-film scaffolding' (1988), and Michael Wilmington accuses it of being 'sub-Spielbergian stuff' and 'hopelessly copycat' (1987). 
It is curious, however, that a sub-standard film would provoke such strong opinions, and that a copycat would be remembered decades later as a classic of the horror genre. Instead, as concerns over the corruption of the horror genre and the corruption of the moral values transmitted to children is frequently mentioned, it seems to be the case that The Gate evoked anxieties over the possibility that both the genre and the demographic were in transition toward new paradigms specifically, that a new demographic, the pre-teen, might have emerged as a de facto audience for horror.

The article is divided in two sections. In the first, I will focus on the external tensions reflected in the film's critical reception, mainly referring to the horror genre and its relationship with children. The analysis focuses on comparing and contrasting creative intention and critical opinion on notions of what the horror genre is or should be (regarding its intensity, its rating and its audience), and moral panics triggered by transitioning social values, proposing a climate of extreme ambiguity and uncertainty over the boundaries of horror. The second section examines the internal ambiguities of The Gate regarding children and horror. Here my analysis will be framed around the tension between Nankin and Takács and their respective attitudes toward horror and childhood. Their conflicting views are reflected in the text, specifically in its representations of children: starting out as Othered figures, in line with traditional horror representations (Wood 2003; Paul 1994; Lury 2010), the children are eventually empowered. The triumph of a more child-centred horror narrative points toward a desire to move away from traditional assumptions about children in horror, as well as children as audiences of horror.

\section{Blurring boundaries: horror audiences, moral panics and PG-13}

Two issues seem to have been of particular interest to critics and reviewers of The Gate: assumptions about children; and the horror genre. These topics were often discussed together, in a way reminiscent of the controversies that first prompted the creation of PG-13, with frequent mention of ideas of cultural dominance and morality. In this section, I will discuss the confusion, disappointment and even anger subjacent to some critics' opinions on The Gate, contrasting them with examples of positive reception and statements made by Takács on the film's intentions. In so doing, I will demonstrate the persistent social and cultural tensions around the topics of children, horror, their boundaries and the moral values implicit in them.

One of the strongest voices against The Gate and similar horror films aimed at young audiences came from critic Kim Newman:

With children, adolescents or childish young men in the leads, [...] [films like The Gate] provide the MTV generation with something to watch every three minutes but are unable to get seriously scary, or even seriously funny. All they prove is nobody needs a safe horror picture. $(1988,204)$

This is a strong statement but it contains an interesting paradox: even as Newman acknowledges that he does not belong to the audience of these films - as he puts it, the 'MTV generation' - he still critiques the feature with reference to the values and judgements of the social group and audience segment to which he himself belongs (that is, the adult viewer). In so doing, Newman is working from the assumption that this latter group is somehow the 'right' audience for the genre of horror and that by catering to the desires of a different, 'lower' group, filmmakers are sinking the genre's standards. This is a problematic stand, not only because Newman disregards the fact that genre 
definitions are fluid (Geraghty and Jancovich 2008), but also because of his failure to consider that what is 'safe' for an adult might indeed be 'seriously scary' for a child.

Similar thoughts are expressed by Andrew Dowler in his review: 'At worst, [The Gate is] flat and pointless. At best, though, there's nothing great, nothing to give any but the least experienced viewer a rush of real pleasure or thrill' (1987). Like Newman, Dowler appears to have a very strict idea about what is and is not horror - the writer even opens his review with a lengthy distinction between 'extreme horror' and the mainstream ('horror for people who don't like horror'). The idea of different kinds of horror for different kinds of audiences seems to evade Dowler beyond the extreme/mainstream divide: at one point, the critic illustrates The Gate's inferiority by referencing the extreme ('real horror') way of handling characters, citing as his example Evil Dead II (Sam Raimi, 1987) - an adult-oriented film rated X in the United States and R in Canada (Dowler 1987). This preconception of horror's default demographic impedes him, like Newman, questioning if those 'least experienced viewers' (that is, children) could perhaps be the very audience targeted by this film.

What we may also deduce from both Newman and Dowler's positions is that in this case, the film's genre trumped its rating when it came to audience expectations: the PG-13 label was in itself not enough to suggest that The Gate might be articulating a child-friendly level of terror, thus revealing the still-ambiguous position of this classification in the industrial and cultural contexts. For these two authors, the genre of horror holds strong connections with a certain rawness of visuals, themes and narratives that is, in their view, unsuitable for children. Moreover, both authors express the idea that to scale down the film's intensity is equivalent to lowering its quality and appeal, therefore implying strong notions of an adult-dominated cultural environment.

These attitudes are often mentioned by director Tibor Takács in interview:

I remember at the time people were always comparing The Gate to A Nightmare On Elm Street [Wes Craven, 1984] or something where to me the films had a completely different type of audience. The movie was always intended for tweens. (Saucedo 2012)

Again, the idea of confusion surrounding the film's audience seems to be linked to the strong cultural associations inherent to the horror genre. Despite having been established three years prior to the release of The Gate, PG-13 does not seem to have yet built a strong identity. This is further evidenced in the way The Gate is remembered and how it is interpreted by today's viewers, particularly with regards to their expectations from a 1980s' horror film. In the DVD feature commentary, Takács comments on the disappointment felt by some viewers at the film's ending, which, as the director explains, some modern horror fans describe as 'a cop out' (Takács, Nankin and Cook 2009). As Takács has expressed elsewhere in interviews, 'Sometimes people forget it's a PG-13 movie for kids and try to match it for gore and intensity against R-rated 80s horror classics. It's really a different animal' (Orange 2009).

This perspective further underlines the idea of ratings as ambiguous reference points. Speaking about the production process of the film, the director has revealed that 'some people wanted it to be an R' (referring to the level of violence, intensity and gore used in the film), but for the director, PG-13 was the only option 'or it wouldn't make any sense' (Takács, Nankin and Cook 2009). In the director's view, the concept of children digging up a hole to hell was 'strictly the fantasy of an eleven-year-old. I don't think many fifteen or sixteen-year-old were going to be thinking about that' 
(ibid.). For Takács, the rating to aim for must match the film's content and target audience rather than its genre expectations. Furthermore, the director suggests very clear demographics for each rating - pre-teens for PG-13 and teenagers for $\mathrm{R}$-, as well as clear thematic trends: for example, adventure, family and personal empowerment in PG-13 films like The Gate, and romance and sexuality in R-rated franchises such as Nightmare on Elm Street and Friday the $13^{\text {th }}$ (Sean S. Cunningham, 1980).

Nevertheless, the fact that this distinction does not appear to be readily made by horror fans in relation to the films of the 1980s indicates the degree to which PG-13 was not universally perceived to be a child-oriented classification, particularly when applied to a horror film. Collective agreement was never reached on the right classification for The Gate franchise: when plans for The Gate 2: The Trespassers (Takács, 1990) were made, the filmmakers were instructed by producers to aim for an $\mathrm{R}$ rating, despite the sequel remaining very close in spirit to the original. Coincidence or not, The Trespassers was not a commercial success.

These ideas about the horror genre and its suitability or lack thereof for children have a certain morality implicit to them. Concerns about the potential message children might get from watching The Gate are a key point in several reviews, most notably Andrew Dowler's characterisation of the film as a 'vicious, venal lie' which, he continues, undermines

the value of truth, truth presented as fable or allegory so that all of us, and especially the kids, can see quite clearly the operations of good and evil, virtue and vice, innocence and experience, strength and weakness - the actions of human beings and their consequences - particularly their consequences. [...] [The Gate] denies all your hard-earned knowledge and all the knowledge you hope and pray your kids are going to grow into. (Dowler 1987)

This paragraph shows a very specific notion of good values, based on the experiences and models of the older generations. On the subject of death, for example, this critic repudiates The Gate's choice of bringing characters back to life in its 'impossibly happy ending': 'This is a movie that feeds into that infantile misapprehension' that death can be reverted (ibid.). By contrast, Johanna Steinmetz, writing for the Chicago Tribune, read the film as morally sound and life-affirming. She begins with the words 'once upon a time', and repeatedly evokes the idea of fairy tale narratives and a family-friendly atmosphere, 'perfectly adapted to living room viewing' (Steinmetz, 1987). She eventually defines The Gate thus:

This is good-natured terror [...] This is terror with a moral (the trouble starts when the parents leave their kids alone for the weekend). And this is terror with a heart (nobody stays dead). (ibid.)

In the same spirit, for critic Gordon Walker at the core of The Gate is 'a charming fantasy-fable about love' with a 'shamelessly positive' message 'to and about young people' (Walker, 1988). With no mention of 'the MTV generation', its moral and cultural decadence or the state of the horror genre, these critics embody a different set of values and beliefs about childhood, the place of children in wider cultural spaces and what comprises child-appropriate viewing. That such different viewpoints existed in relation to the same text suggests a moment of transition in social attitudes, particularly as the more strongly worded criticisms are those which directly relate to change, either in perceptions of horror and its audiences or the moral values depicted in children's entertainment. 


\section{Demons or demon-slayers? Representations in between paradigms}

So far, I have shown how opposing views on childhood and horror were circulated in the critical reception of The Gate and argued that this split points toward a moment of change. In this section, I will reinforce this argument by analysing the differences of opinion and creative vision between the film's director and writer. By referring to divergences during production and, more specifically, to the film's representations of children, I will suggest that The Gate as a text is, like its reception, positioned in between different perspectives on the position of children in relation to horror.

In Michael Nankin's original draft of The Gate, Glen and Terry were younger children, respectively eight and nine years old. The characters were later aged up (as played by Stephen Dorff and Louis Trip respectively) in order to match the film's new direction as a family-friendly feature. In the DVD feature commentary, Nankin expresses reservations about the success of the change, revealing that he 'never quite felt like [he] really made the characters old enough.' These hesitations are in contrast with Tibor Takács' own feelings on the subject: 'I always thought they were ageappropriate [...] They're plain ten-year-old [...] That's part of the charm of the movie, the reality of those kids' (Takács, Nankin and Cook 2009).

This disagreement between Nankin and Takács is one of many which reflect the two filmmakers' clashing opinions about children and childhood. On this specific instance, the two demonstrate different approaches to Glen and Terry's demographic: while Nankin has trouble evoking a clear picture of a pre-teen, Takács seems to know this group's 'reality'. More than an instance of one filmmaker being right over the other, this divergence suggests different understandings of childhood and its boundaries. Nankin segments childhood in two (young children and teenagers) and therefore has trouble picturing a character in between, whereas Takács appears to recognise childhood as a more complex and segmented period.

These opposing views are also revealed in the film's representations. Let us first look at Michael Nankin's thoughts on the child characters:

Everything they do is wrong. Everything they do they're not supposed to do, or is cruel, or is dangerous. And they basically get what they deserve. [...] I always thought horror movies become scarier if your protagonist deserves bad things. You're just waiting for them to get their come-uppance. (ibid.)

This quote is reminiscent of film scholar William Paul's thoughts on children in the horror film, particular the popular figure of the demonic child. For Paul, characters of malevolent children engage the (adult) audience's notion of 'physical harm for the child's own good,' (Paul 1994) and dramatically focus on the pleasure the adult viewer finds in the discovery of evil in the child as well as in its eventual punishment. These child characters are described by Paul as being on the cusp of puberty and possessing a disturbing balance of precociousness and regressiveness in their character and behaviour.

Their precociousness often relates to the difference between what they know or do and what is socially perceived to be the appropriate behaviour or level of knowledge for a child (notions of displaced sexuality, for example, are often explored) (Paul 1994, 282-283). Other authors have studied this horror archetype, including Robin Wood, who dubbed it the 'Terrible Child' (2003). This way of representing children can be seen to be related to a particular set of social and cultural 
beliefs about children and childhood, specifically the idea that children are vulnerable innocents, in opposition to adults, who must bear the weight of knowledge about life but are also better equipped to make good decisions (Jenkins 1998). It is not difficult to find similarities between the Terrible Child and the characters of The Gate. In fact, elements of the script and the mise-en-scene often explicitly point towards it, such as Glen's tree-house (a symbol of childhood) having been built on a tree which is literally rooted in hell; or the damage left on the roof of the house by Glen's rockets, reminiscent of Carrie's apocalyptic fury in Brian de Palma's horror classic of 1976. But it is through the characters of Glen and Terry that The Gate refers most specifically to the evil child tradition in horror.

Terry, for example, is described by Glen's father as confused, angry and destructive; traits that are attributed to his lack of adult supervision and which he expresses through his enjoyment of acts of mild animal cruelty. Furthermore, his unconventional image is in sharp opposition to the traditional picture of the wholesome child: Terry dresses 'tough' (in dark colours, death imagery, and band patches on his jacket), listens to heavy metal music and lives in a bedroom covered top-to-bottom in band posters and images of demons and the occult. Terry's special relationship with the unseemly forces of demons and pagan mythology is further explored in one of the film's later plot points when Terry becomes a demon and turns against Glen - a warning, perhaps, of the effects of keeping bad company.

This idea of Terry as a bad influence is matched by Glen's extreme vulnerability: as Glen says at one point in the film, he would jump off a bridge if Terry did. Unlike Terry, Glen is under constant adult supervision and relies on his parents, the babysitter, his older sister and Terry for protection and guidance. This reliance on authority, however, does not stem from the boy's exemplary obedience but from his crippling insecurity which later leads to overwhelming feelings of guilt and a fear of/desire for punishment. These feelings of guilt initially appear out of place but have been intentionally planted in the script by Michael Nankin, who often refers to Glen's guilt during his feature commentary. For example, when describing Glen's emotional state during one of the first scary scenes with the demons, Nankin speaks not of anxiety or fear but of guilt (Takács, Nankin and Cook 2009). This guilt is presumably Glen's response to his parents' anxieties and their mistrust of his character, and closely relates to the overwhelming punishments delivered to (and, in part, desired by) him: in Glen's mind, if his parents think he is capable of being bad then he must be so; and if he is bad, he must be punished.

The articulation between Glen's guilt and his simultaneous fear of and desire for punishment is very clear in Nankin's 'favourite scene', in which the demons incarnate Glen's parents. Believing these demon-parents to be real, Glen runs into their embrace - only to hear his demon-dad roar, 'You've been bad!' and attempt to strangle him to death. Glen is eventually able to defend himself by pushing his fingers into his demon-dad's eyes until his head erupts in a pulpy mess. Glen looks at his hands in shock and horror: they are covered in his father's 'blood'. Nankin describes this scene as 'five really good ideas: the parents come home, you've been bad, dad tries to kill you, you kill your father while your mother laughs' (Takács, Nankin and Cook 2009). This description suggests strong negative emotions: the guilt of having non-filial thoughts and of disappointing, as well as the fear of punishment and of humiliation - all of these are central to Glen's character.

These representations, alongside their creator's comments, are illustrative of a particular view of children. This perspective can be linked to the horror genre's tradition in representations of children 
(both as evil and as vulnerable innocents), but it also circulates certain social and cultural positions of its time, namely certain firm-handed parenting styles of the period (Stearns 2003), and a number of anxieties related to children and the potential negative effects of external influences - horror films, as suggested by The Gate's own critical reception, but also comic books, heavy metal music and the depiction of violence and amoral behaviour in the media (Medved 1993; Barker and Petley 2001).

But while the representations in The Gate circulate all of the above, they also negotiate a different perspective. Takács comments emerge as a counter-point to Nankin's views: for the director, the film's intent was to tap into 'nostalgia about childhood and, if you're a kid, your experience as a kid' but it was important that it not be 'mean-spirited', a characteristic Takács felt was overpowering in 1980s' horror (Takács, Nankin and Cook 2009). Instead, he wanted to tell a story that was enchanting. This desire, coupled with the film's strong commitment to stay with the children's point of view, is part of what altered the tone of the film and its representations. In Takács vision, The Gate was not a film about children being demons or worrying that they might be; rather it was about overcoming demons, about children 'empowering themselves' (Saucedo 2012).

This attitude comes across most clearly in Glen's character development. In the first two thirds of the film, Glen is a cowering, weepy picture of sadness, stuck in a routine of running, hiding and submission. As the film progresses, however, Glen transforms into a driven, strong and confident child. Two scenes illustrate this progression. First, the resolution to the 'You've been bad!' sequence. Although this segment reveals the extent of Glen's anxieties through a symbolic patricide and illustrates the boy's feelings by showing the 'blood' on his hands, it ends on a note of innocence: the 'blood' magically disappears from Glen's hands, much to his amazement - his blame has been lifted. The second illustration comes at the end of the film, after Glen banishes the Demon Lord back to hell. The film's colour palette sets the tone: dark clouds dissipate and a new dawn shines through, its rays reaching the hero boy. Later on, this new beginning and the idea of Glen as a new child is apparent in his body language: chin up, chest out, a confident stride and a happy smile on his face. Thus, in the end Glen defies rather than conforms to expectations of the vulnerable child.

Likewise, Terry ultimately proves a parody of the evil child as the film deconstructs his 'tough' image: while listening to his heavy metal records, Terry jumps on his bed and, throwing his rainbow bedcover around his head like a cloak, pantomimes the lyrics. These child-like touches are supplemented with suggestions of his vulnerability, both physical and emotional: his 'nerdiness' (skinny body, glasses), as well as his grief over his mother's recent death and the impossibility of finding comfort in his absent father. Critical perception of his character is also telling: one reviewer describes Terry as especially 'cute' in his suggestion of the 'owlish curiosity and sarcasm of a bookish 12-year-old' (Wilmington 1987); another speaks of him as a 'lonely child' (Steinmetz 1987). These comments indicate that two of his Terrible Child attributes - his knowledge of adult secrets and his destructiveness - were not perceived to be evidence of a dangerous nature. Instead, the former was seen as a product of positive curiosity and the latter a result of Terry's sadness. Furthermore, this reception shows that Terry elicited sympathy from adult viewers, a notion that does not apply to traditional evil child characters. 
These details and developments within the characters of Terry and Glen reveal a nuanced negotiation of different perspectives of childhood within The Gate. If on the one hand, there are suggestions of child characters as projections of adult anxieties and reflections of traditional ideas about children and innocence, on the other, The Gate seems to want to move away from these attitudes and into a more segmented and complex notion of childhood. As the critical reception also indicates, the juxtaposition of these two views suggests the tensions and struggles of a period of social change.

\section{Conclusion}

In this article, I have demonstrated The Gate to be a film caught in a transitional moment. From its production to its reception, this is a feature marked by ambiguity, tension and the struggles of negotiating different, often opposing, perspectives and attitudes about both children and the horror genre. As my analysis has shown, many of the debates around The Gate were to do with the ongoing change in social attitudes about children, specifically the unresolved issue of the pre-teen as a separate social group from teenagers and younger children. The struggles around this topic were reflected in the anxieties around PG-13 (Vaughn 2006 117), particularly where the rating could be applied to previously-restricted material.

This uncertainty was striking when the new classification was tied to the horror genre, which in previous decades had been strongly associated with films which were heavy, dangerous and not child-friendly (Newman 1988) - the opposite of what the PG-13 classification appeared to promise as it was opened up to minors. Indeed, to achieve the PG-13 rating with a horror title, filmmakers needed to tailor their material to the unrestricted audience. This included a lowering of the intensity and violence but also, and perhaps most importantly, a change in point of view.

This shift in perspective is what The Gate illustrates. In order to make the film more appealing for the demographic he wished to target, Takács chose to base his narrative on child-friendly themes, such as adventure and friendship, instead of the more common theme of sexuality found in teenoriented films of the same period, such as the Friday the 13th or Nightmare on Elm Street series, or the social concerns of adults expressed in films like Deliverance (John Boorman, 1972) or The Exorcist (William Friedkin, 1973). Additionally, the child was given a far more central role. This is not to say that the child had been ignored in horror previously; on the contrary, it proliferated, but heavy with Otherness, in the figures of a sociopath, a demon, the Antichrist, an alien, a ghost and so forth (see Wood 2003; Paul 1994; and Lury 2010). Bringing the child to the centre, therefore, implied not added visibility but added humanity. In The Gate the child character metamorphoses from an object of repulsion to an object of identification and empowerment for the viewer.

This is a major transition for horror. Not only does it challenge recurrent horror motifs and trends, it disputes a common assumption about the genre's proper audience. This was not without opposition, as the conflicted reception of The Gate illustrates. What its example reveals is not a moment of complete transformation in the horror genre but a period of adaptation, conflict and emerging attitudes, with repercussions lasting to the present day, when horror aficionados still discuss the problem of the 'deterioration' of horror. The aim of this article was not to resolve this conflict but to point out the relationship between its beginnings and other cultural and social transitions of the period: a reconfiguration of the concept of childhood and the introduction of the PG-13 rating. 


\section{References}

Barker, M. and Petley, J. (2001) Ill Effects: the Media/Violence Debate, London: Routledge Box Office Mojo 'The Gate' Accessible at http://www.boxofficemojo.com/movies/?page=main\&id=gate.html. Accessed 20 January 2014

Crow, D. (2013) 'New Carrie TV Spot Warns of R-Rating', DenOfGeek.us, [online], 23 September. Accessible at http://www.denofgeek.us/movies/carrie-remake/196688/new-carrie-tv-spot-warns-ofr-rating. Accessed 27 December 2013

Dowler, A. (1987) 'The Gate', Cinema Canada, July/August. Accessible at http://cinemacanada.athabascau.ca/index.php/cinema/article/view/3659/3697. Accessed 13 January 2014

Geraghty, L. and Jancovich, M. (2008) 'Introduction:Generic Canons' in Geraghty, L. and Jancovich, M. (eds) The Shifting Definitions of Genre: Essays on labelling Films, Television Shows and Media London: McFarland \& Company, Inc., 2008 pp. 1-12

Jenkins, H. (1998) The Children's Culture Reader, New York: New York University Press Lury, K. (2010) The Child in Film: Tears, Fears and Fairy Tales, London: I.B. Taurus Lynch, T. (2013) 'Carrie Secures an R Rating, Is Poised to Capture the True Horror of Adolescence', Grantland.com, [online], 24 September. Accessible at http://www.grantland.com/blog/hollywood-prospectus/post/ /id/87903/carrie-secures-an-r-rating-ispoised-to-capture-the-true-horror-of-adolescence. Accessed 27 December 2013

Medved, M. (1993) Hollywood vs America, New York: Harper Perennial

Newman, K. (1988) Nightmare Movies: A Critical History of the Horror Film, 1968-88, rev. ed., London: Bloomsbury

Orange, B. A. (2009) 'Exclusive: Tibor Takács Takes Us Back Through The Gate: Monstrous Special Edition', MovieWeb.com, [online], 20 October. Accessible at http://www.movieweb.com/news/exclusive-tibor-takacs-takes-us-back-through-the-gate-monstrousspecial-edition. Accessed 5 September 2013

Paul, W. (1994) Laughing, Screaming: Modern Hollywood Horror and Comedy, New York: Columbia University Press

Prince, S. (2000) A New Pot of Gold: Hollywood Under the Electronic Rainbow, 1980-1989, New York: Scribner

Saucedo, R. (2012) 'Badass Interview: The Gate's Tibor Takács', BadassDigest.com, [online], 9 February. Accessible at http://badassdigest.com/2012/02/09/badass-interview-the-gates-tibortakacs/. Accessed 5 September 2013

Stearns, P. (2003) Anxious Parents: A History of Modern Childrearing in America, New York: New York University Press

Steinmetz, J. (1987) 'Terror Swings With Humor in The Gate', The Chicago Tribune, 18 May. Accessible at http://articles.chicagotribune.com/1987-05-18/features/8702060728_1 tibor-takacsterror-william-beeton Accessed 20 January 2014

Thompson, K. (2004) 'Violence, Sex, and Profanity in Films: Correlation of Movie Ratings with Content', Medscape General Medicine, 6(3), 3

Vaughn, S. (2006) Freedom and Entertainment: Rating the Movies in an Age of New Media, Cambridge: Cambridge University Press 
Walter, G. (1988) Magill's Cinema Annual 1988, New York: Salem Press

Webb, C. (2012) 'MTV Geek's Frightful Faves: Reopening 'The Gate' (1987)', MTV.com, [online], 10 October. Accessible at http://geek-news.mtv.com/2012/10/10/mtv-geeks-frightfulfaves-reopening-the-gate-1987/. Accessed 5 September 2013

Wilmington, M. (1987) 'Movie Review: Bevy of Beasties Run Wild in The Gate', Los Angeles Times, 19 May. Accessible at http://articles.latimes.com/1987-05-19/entertainment/ca1111_1_movie-review Accessed 10 January

Wood, R. (2003) Hollywood from Vietnam to Reagan - and Beyond, rev. ed., New York: Columbia University Press

\section{Filmography}

Takács, T., Nankin, M. and Cook, R. W. (2009) Audio commentary, The Gate (Monstrous Special Edition) (Tibor Takács, USA/Canada, 1987) 